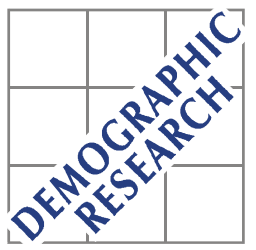

Demographic Research a free, expedited, online journal of peer-reviewed research and commentary in the population sciences published by the Max Planck Institute for Demographic Research Doberaner Strasse 114 D D-18057 Rostock · GERMANY www.demographic-research.org

DEMOGRAPHIC RESEARCH

VOLUME 5, ARTICLE 6, PAGES 187-216

PUBLISHED 11 DECEMBER 2001

www.demographic-research.org/Volumes/Vol5/6/

DOI: 10.4054/DemRes.2001.5.6

\title{
The High Fertility of College Educated Women in Norway:
}

\section{An Artefact of the Separate Modelling of Each Parity Transition}

Øystein Kravdal

(C) 2001 Max-Planck-Gesellschaft. 


\section{Table of Contents}

1 Introduction 188

2 Data 192

$3 \quad$ Some Simple Measures of Educational 193

$4 \quad$ Models Estimated from Register Data 197

$\begin{array}{lll}5 & \text { Simulations } & 203\end{array}$

6 Models Estimated from Survey Data 208

$\begin{array}{lll}7 & \text { Summary and Conclusions } & 210\end{array}$

8 Acknowledgements 213

$\begin{array}{ll}\text { References } & 214\end{array}$ 


\title{
The High Fertility of College Educated Women in Norway: An Artefact of the Separate Modelling of Each Parity Transition
}

\author{
Øystein Kravdal ${ }^{1}$
}

\begin{abstract}
College education has a positive impact on birth rates, net of age and duration since previous birth, according to models estimated separately for second and third births. There are also indications of such effects on first-birth rates, in the upper 20s and 30s. Whereas a high fertility among the better-educated perhaps could be explained by socioeconomic or ideational factors, it might just as well be a result of selection. When all three parity transitions are modelled jointly, with a common unobserved factor included, negative effects of educational level appear. On the whole, the effects are less clearly negative for women born in the 1950s than for those born in the 1940s or late 1930s. The cohorts from the 1950s show educational differentials in completed fertility that are quite small and to a large extent stem from a higher proportion of childlessness among the better-educated. Second-birth progression ratios are just as high for the college educated as for women with only compulsory education, and the third-birth progression ratios differ very little. This reflects weakly negative net effects of education after first birth and spill-over effects from the higher age at first birth, counterbalanced by differential selectivity of earlier parity transitions.
\end{abstract}

1 Department of Economics, University of Oslo, P.O. Box 1095 Blindern, N-0317 Oslo, Norway, Tel. (47) 22855499, Fax: (47) 22855035, Email: okravdal@econ.uio.no. 


\section{Introduction}

A sharp negative relationship is generally found between a woman's completed fertility and her educational level. One important exception is that a few years of primary education tend to push fertility up in some very poor or highly gendered societies (e. g. Jejeebhoy 1995). This is, above all, due to a shorter period of breastfeeding or postpartum abstinence among these women, which are mechanisms of no relevance for fertility in contemporary industrialized countries. In our part of the world, completed fertility has usually been found to decrease quite sharply with increasing educational attainment, but studies from some countries have shown a narrowing gap in recent years. For example, it was seen in Norwegian data that the educational differentials in average cohort fertility at age 35 were somewhat less pronounced for the 1954 cohort than for the 1945 cohort, and partly because of the much weaker educational gradients in the third-birth progression ratios in the younger cohort (Kravdal 1992a). Moreover, the lower fertility that still showed up among the better-educated seemed to be produced entirely by their later entry into motherhood: When it was compared among women who had their second child at the same age, the college educated were, in fact, more inclined to have a third child within five years than those with only compulsory education. This net effect appeared to become increasingly positive during the 1970s.

Similarly, hazard regression models based on Swedish (Hoem and Hoem 1989) and German (Huinink 1989) data revealed positive effects of education on birth rates, net of age. British demographers, however, reported that education had no net effect (Wright et al. 1988).

A weakening negative effect of a woman's education would not seem unreasonable, especially in countries such as Norway and Sweden, where many mothers with young children are in the labour force. Less income is foregone in response to childbearing now than a few decades ago, not least because of improved access to and stronger accept for purchased child care. This means that the wage-dependent opportunity costs are substituted by child care costs that depend quite little on income (see also Ermisch 1989). (In support of this, it has been reported by Kravdal (1996) that education effects are less negative in Norwegian municipalities with relatively good supply of day care than in other municipalities.)

Also other forces might produce a less pronounced negative effect of education among women born in the 1950s than those born some years previously (preceded by an opposite development in an even earlier period, as further dealt with below). For example, there are some indications that the of use modern efficient contraception in Norway increased first among the better-educated, followed by a diminishing gap (Østby 1989). Moreover, one may speculate whether the normative pressure to have a least two children (e.g. Blake 1968) perhaps has weakened first for the better-educated 
and subsequently for other social groups. Finally, there may have been a diffusion not only of norms, but also childbearing preferences. We have very meagre knowledge about the value placed on childbearing compared to other sources of satisfaction available at the same price, but some studies have suggested a general drift towards weaker childbearing preferences (see e.g. Crimmins et al. 1991), and if such a process has actually occurred, the better-educated are not unlikely to have been forerunners.

While a diminishing negative effect in recent years might seem plausible, it is more difficult to understand how a high education could turn into a stimulating factor. The better-educated women have a higher income themselves, and their spouse, if any, will also tend to have higher earnings. If people's material aspirations and their child 'quality' requirements were determined by the average income level in society, rather than their own economic strength, the groups with a relatively high income would display a high fertility. However, positive income effects are very rarely seen, which suggests endogenous 'quality' requirements and a 'quantity'- 'quality' trade off in favour of the latter. For example, a higher income for husbands was found to reduce third-birth probabilities in the Norwegian study mentioned above (Kravdal 1992a). One might also suspect that the more stable unions among the better-educated are partly responsible for the positive education effects. However, the effects have been seen also in models estimated for the married exclusively (Kravdal 1992a). Another possible reason could perhaps be that the combination of paid work and family responsibilities is less stressful for college educated women, who often get jobs with more flexible work schedules. Finally, it is possible, in principle, that the preferences for childbearing not actually have weakened particularly much among those with little education in recent years, and thus approached the level among the better-educated (as suggested above), but that the latter have started to appreciate more strongly the emotional returns to parenthood. This is, of course, pure speculation, but should there be a movement towards more 'childfriendly' preferences (after what may have been a development in the opposite direction), it would not be surprising to see the 'cultural elite' taking the lead.

A completely different explanation would be that the positive education effect is due to selection. As a simple illustration of this idea, let us assume that there are two groups of people that cannot be distinguished in the data, those with a high-fertility proneness that sticks to them throughout their reproductive period, and those with a lowfertility proneness. For example, the latter may consider children a relatively unimportant source of emotional satisfaction or be sub-fecund. Let us further assume, for simplicity, that there is a 50\%-50\% distribution of this unobserved factor at age 15 both for women (who end up) with a high education and those with little education. Among women with little education, those who score high on this unobserved factor have perhaps their second child at, say, age 23 on average, whereas those who score low perhaps have it at age 27. (Besides, a larger proportion of the latter would not have a 
second child at all.) The corresponding ages for the better-educated would be higher (not least as a result of their school enrolment itself), perhaps 28 and 32 years. Thus, when we compare among women who, for example, at age 32 had their second child two years before, those with low education would tend to have very low score on the unobserved factor on average, whereas those with high education would have a score around average. That could well be the reason for their higher third-birth rate.

This idea that the meaning of age at second birth differs across education was implemented in a third-birth model by Hoem (1996). She included relative age, defined as the age at second birth compared to the average for women with the same education. With this specification, the positive education effect vanished completely in her Swedish data. A similar result was reported by Hoem et al. (2001) in a study of Austrian fertility.

A more direct way to capture the importance of unobserved heterogeneity would be to estimate a joint model for first, second and third (and possibly even higher-order) birth rates, and include an unobserved factor allowed to influence all of these rates. The main objective of this study is to check whether a positive education effect shows up also with such an approach. If it does, identification of its causes would be an important goal of future research. Should a positive effect really exist, and hinge on such factors as preference structures or job-family compatibility, it might signal a generally increasing fertility in the future, as the better-educated perhaps may be 'avant-gardists' in these respects. If relative resources are the key factor, the message is not the same.

As a first step, estimates from such a joint model are compared with those obtained from a traditional, separate modelling of first, second and third births. For simplicity, fourth and higher-order births are ignored.

Besides, changes over time are addressed. It is checked whether the less negative (or more positive) effects of education in the younger cohorts also appears when unobserved heterogeneity is taken into account. The focus is on cohorts who had reached age 40 when the data were collected, and therefore largely completed childbearing. It is primarily the college educated and those with only compulsory education who are compared. 'College education' is defined as 13 or more years of schooling, with 13-14 years denoted as 'short college education' and more than 14 years of schooling as 'long college education'.

Register data for the entire Norwegian population are employed. In lack of continuous education histories for the entire reproductive age span, the educational level at about age 40 is used. In principle, this is not a good solution, as the estimated effects will capture not only how birth rates at a given age are influenced by current education (i.e. educational level and activity at that age), but also the effects of births on later educational attainments. As an example of such reverse causality, an unplanned birth can make it impossible to realise original educational goals, or the goals may be revised 
upwards in case of an unexpected childlessness. In both cases, the true effects of education on fertility would be less negative than suggested by the estimates.

Stated differently, a simple, but incomplete, picture to have in mind would be that the educational level included in the models is a proxy for an educational goal that people stick to from the very beginning of their reproductive period, and that influences birth rates at any given age, not least through the enrolment status and educational level attained at that age. For example, the estimated effect of college education on fertility at age 20 might be thought of as the impact of having completed high school, being currently enrolled, and having plans about more years at school at that age. This interpretation would be particularly inadequate for first births. For second and third births, however, it should not be such a great mistake to consider the estimated effects as reflecting the importance of current educational level on birth rates, because there is generally quite little educational activity after entry into motherhood, regardless of further childbearing.

Many readers may be unfamiliar with such a model with persistent unobserved heterogeneity, so its characteristics are illustrated by simulation. This also serves the purpose of demonstrating how well the model fits the data.

Positive effects of educational level have been noticed for first births as well. There is, of course, no doubt that those who end up with a high education have their first child at a higher age, and that a relatively large proportion remain childless. However, this might well be due to their low birth rates while they are enrolled in school. The educational level itself does not necessarily have to be inversely related to the first-birth rate. To check that, both the current educational level and activity (which are correlated) must be included as time-varying variables, rather than including the education at the end of the reproductive period. With such an approach, Blossfeld and Huinink (1991) found that the longer time at school was a key determinant of delayed childbearing in Germany, whereas the resulting increase in educational level (presumably operating in part through a higher price of the woman's time) had virtually no impact on first-birth rates. A quite similar pattern appeared in a Norwegian study (Kravdal 1994). For example, among women above age 25 , the highest first-birth rates were actually found among the college educated (net of activity status). This was from a material covering the period from the mid-1960s to the mid-1980s, and changes over time were not checked. In support of this, Santow and Bracher (2001) found positive education effects on first-birth rates among married women in Sweden, and an American study (Martin 2000) showed that education effects after age 30 became positive after the mid-1970s.

Just as for the higher-order births, such a positive estimate could reflect a truly stimulating effect, or alternatively stem from selection: Those with little education who have still not become mothers at such an high age may score low on some unobserved factors of importance for fertility. 
In this study, it is checked whether a positive effect of educational level on firstbirth rates at relatively high ages also appears when a joint model is estimated. The Family and Occupation Survey of 1988, which contains continuous schooling biographies, is used for this purpose.

Before presenting the model estimates, a simple description of completed fertility and parity progression ratios is first given.

\section{Data}

Both survey data and register data are used in this analysis. The register data include all women born 1936-83 who have been assigned a Norwegian personal identification number, i.e. who have lived in Norway some time after 1960. Birth histories up to 1997, established from the Central Population Register, are virtually complete for these women. Time of death or last emigration, if any, is also recorded. Such data have been used in many other fertility studies, most recently by Kravdal (2000).

The focus is on fertility up to age 40 among the cohorts 1936-57. This cut-off at age 40 is, of course, not critical. According to calculations done for the 1952 cohort, completed fertility is only 0.03 higher at age 45 . The difference is 0.01 for women with only compulsory education and 0.04 at the highest educational levels.

Educational histories, which include the highest educational level achieved as of 1 October the years 1980-82 and 1985-97, as well as the enrollment status at those dates, have been taken from the Annual Educational Statistics Files produced by Statistics Norway. In this study, the education variable refers to the level at approximately age 40 (more precisely in 1980 for the cohorts 1936-40, 1985 for the cohorts 1941-45, 1990 for the cohorts 1946-50, 1995 for the cohorts 1951-55, and 1997 for the cohorts 1956-57).

For simplicity, only women who lived in Norway at age 40 are included in the calculations. This will, in principle, give a slightly biased estimate of Norwegian fertility, as both migration and mortality depend on childbearing, but fertility differentials are certainly very marginally affected. Immigration, if any, is ignored. This has the effect that most births abroad to persons who later moved to Norway are counted, and that immigrants contribute exposure time before they arrive. Because of the modest size of Norwegian immigration, this should be completely unproblematic, and especially in an analysis such as this. (Completed cohort fertility, for all educational groups pooled, is indeed very similar to that calculated with stricter definitions by Brunborg and Mamelund (1994)).

In the Family and Occupation Survey of 1988, individual biographies of pregnancies, cohabitation, marriage, educational activity, and employment were 
collected for 4019 women born in 1945, 1950, 1955, 1960, 1965 and 1968 (and for a smaller sample of men). The non-response rate for women was 19\% (Statistics Norway 1991). The focus in this study is on the 1945 cohort, who had largely completed childbearing at the time of the survey.

\section{Some Simple Measures of Educational Differentials in Cohort Fertility}

Some simple measures of educational fertility differentials at age 40 are shown in Table 1 . The few women with no educational level recorded are included as a separate category.

The gaps in completed fertility have narrowed markedly, because the decline has been restricted largely to women with little education. Above all, the proportion of twochild mothers who eventually have a third child and the proportion who proceed from parity three to four (denoted below as third- and fourth-birth progression ratios, respectively) have dropped much more for women with little education than for the college educated. For example, the proportion of two-child mothers with only compulsory education who also have a third child has declined from $60 \%$ to $40 \%$, whereas the level has remained fairly constant at about $40 \%$ for the college educated born after 1940. The second-birth progression ratios (defined similarly) have changed less, and generally also differ less by education, but the modest changes in the educational gradients are in the same direction as for the higher-order births. Childlessness depends strongly on education, in the older as well as younger cohorts under study. Thus, childlessness is to a large extent responsible for the educational differentials in completed fertility in the younger cohorts. In fact, among women with at least one child, completed fertility in the 1951-55 cohorts differs by only 0.11 between women with a long college education and those with only compulsory education (not shown). According to a simple decomposition, the difference in childlessness is thus responsible for $56 \%$ of the difference in completed fertility between these two groups, and the differences in higher-order births for the remaining $44 \%$.

The quite weak relationship between education and second- and third-birth progression ratios in the youngest cohorts is noteworthy in light of the much higher age at first birth among the college educated (coming on top of their higher proportion of childlessness). The regression models presented below will provide some explanations. 
Table 1: $\quad$ Some cohort fertility measures at age 40, based on data from the Norwegian Population Register.

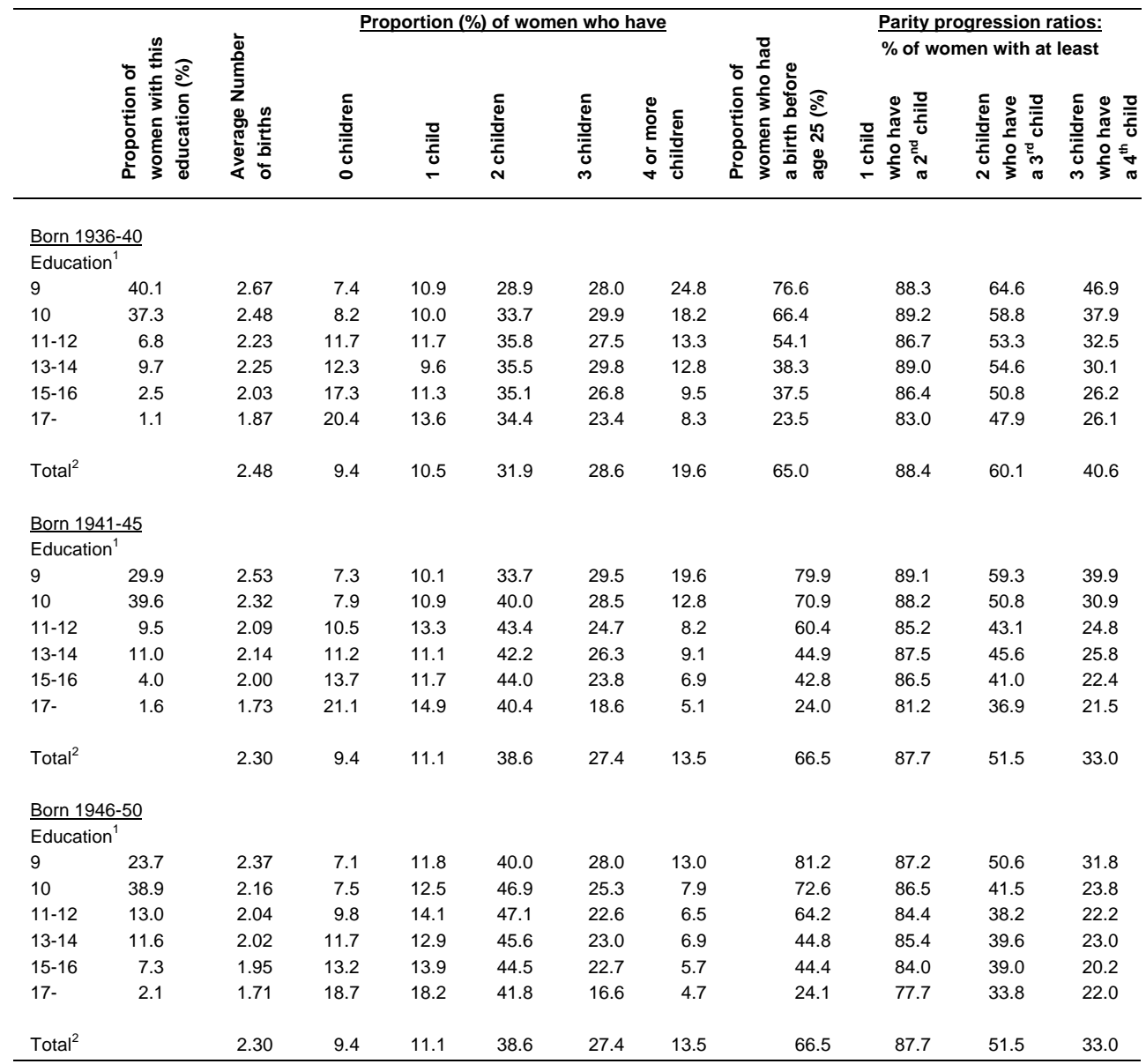


Table 1: (continued)

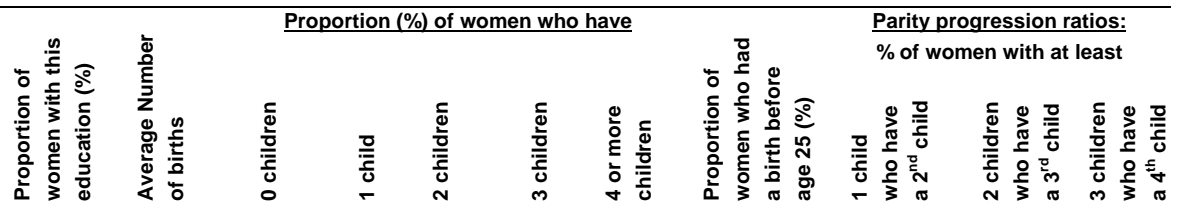

\begin{tabular}{|c|c|c|c|c|c|c|c|c|c|c|c|}
\hline \multicolumn{12}{|c|}{ Born 1951-55 } \\
\hline \multicolumn{12}{|c|}{ Education $^{1}$} \\
\hline 9 & 16.7 & 2.18 & 7.9 & 14.9 & 42.5 & 24.6 & 10.1 & 79.9 & 83.8 & 45.0 & 29.1 \\
\hline 10 & 35.4 & 2.08 & 9.0 & 14.2 & 46.2 & 23.5 & 7.0 & 70.0 & 84.4 & 39.8 & 23.0 \\
\hline $11-12$ & 17.3 & 2.02 & 10.0 & 15.2 & 45.8 & 22.7 & 6.4 & 62.8 & 83.1 & 38.8 & 22.0 \\
\hline $13-14$ & 12.5 & 2.00 & 12.6 & 13.8 & 42.9 & 23.7 & 7.0 & 38.2 & 84.2 & 41.7 & 22.7 \\
\hline $15-16$ & 11.8 & 1.98 & 13.0 & 14.3 & 42.3 & 24.1 & 6.3 & 41.4 & 83.6 & 41.8 & 20.7 \\
\hline $17-$ & 3.0 & 1.78 & 18.5 & 16.9 & 39.3 & 19.7 & 5.6 & 18.7 & 79.2 & 39.2 & 22.1 \\
\hline Total $^{2}$ & & 2.05 & 10.7 & 14.6 & 43.9 & 23.3 & 7.6 & 60.7 & 83.7 & 41.3 & 24.7 \\
\hline \multicolumn{12}{|c|}{ Born 1956-57 } \\
\hline \multicolumn{12}{|c|}{ Education $^{1}$} \\
\hline 9 & 12.7 & 2.17 & 8.8 & 15.4 & 40.9 & 24.4 & 10.5 & 76.9 & 83.1 & 46.1 & 30.1 \\
\hline 10 & 32.0 & 2.09 & 10.1 & 14.4 & 43.3 & 24.2 & 8.0 & 65.4 & 84.0 & 42.7 & 24.9 \\
\hline $11-12$ & 22.4 & 2.00 & 11.0 & 15.2 & 44.1 & 23.5 & 6.2 & 56.0 & 82.9 & 40.3 & 21.0 \\
\hline $13-14$ & 12.0 & 2.01 & 13.9 & 13.2 & 40.2 & 25.7 & 7.0 & 32.0 & 84.7 & 44.9 & 21.5 \\
\hline $15-16$ & 13.9 & 2.00 & 13.3 & 13.9 & 40.2 & 25.8 & 6.8 & 35.4 & 84.0 & 44.8 & 20.8 \\
\hline $17-$ & 3.2 & 1.84 & 18.4 & 15.4 & 37.3 & 22.6 & 6.3 & 15.7 & 81.1 & 43.7 & 21.8 \\
\hline Total $^{2}$ & & 2.05 & 11.8 & 14.6 & 41.5 & 24.1 & 7.9 & 54.2 & 83.4 & 43.6 & 24.7 \\
\hline
\end{tabular}

${ }^{1}$ Years of education, measured at age 40-44 (see text for details)

${ }^{2}$ The 'Total' includes a group with unknown education (about $3 \%$ )

Finally, it should be mentioned that the educational differentials in parity progression ratios have not changed monotonically. The 1950 cohort is a marked turning point for third births. Third-birth progression ratios are less than $4 \%$ lower for the college educated than for women with only compulsory education in the cohorts 1951-57 (see also Figure 1). (The lowest ratios are seen for those with a secondary education.) By contrast, differences are in the range 10-20\% for the older cohorts, with the sharpest gradients appearing for the 1941-45 cohorts. A similar pattern is seen for the generally smaller differences in the second-birth progression ratios, except that the 
sharpest gradient is seen in the 1946-50 cohorts (see also Figure 1). In contrast to this, the development is monotonic for fourth births, with the largest differences between the college educated and those with only compulsory education in the 1936-40 cohorts (see also Figure 1). As fourth births occur, on average, about four years after third births, and the spacing of lower-order births is 3-4 years, this pattern is quite consistent with changes being period rather than cohort driven. In fact, very clear period effects have been seen in previous Norwegian fertility studies (Kravdal 1994, 2000), and some authors have provided strong arguments for their existence more generally (e.g. Ni Bhrolchain 1992). Given the typical ages at the first four births, the maximum educational gap in parity progression ratios would be around 1970 .

Figure 1: Differences in second-, third- and fourth-birth progression ratios between women with long college education (15 or more years of schooling) and those with only compulsory education, by birth cohort.

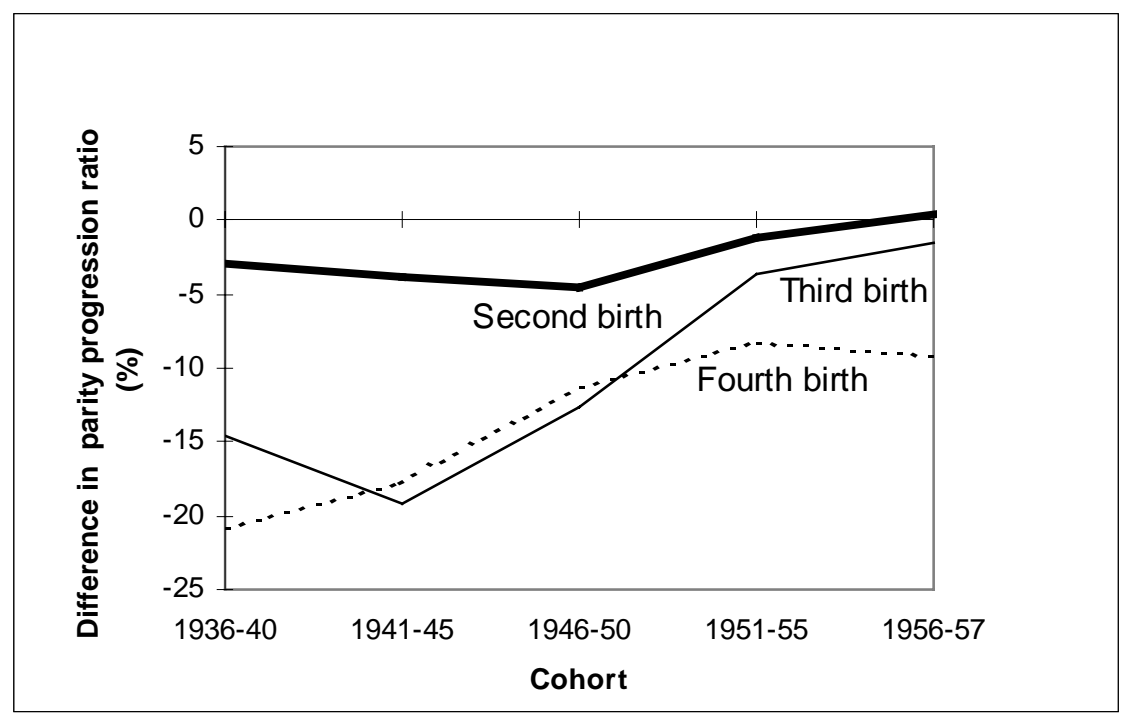




\section{Models Estimated from Register Data}

The release 1.04 of the aML software (Lillard and Panis 2000) is used to estimate birth rate models. As a first step, models are estimated separately for first, second and third births. The follow-up is from age 15 (in first birth models) or from previous birth (in higher-order birth models), and up to age 40. Estimation is first done for the 1951-55 cohorts.

The first-birth rate is assumed to depend only on current age (specified as a spline function), education at (approximately) age 40, and an interaction between the two. The latter is included because, for example, those who end up with a high education are likely to have low birth rates during many years as young adults because of school enrolment, whereas those who take little education are likely to display high birth rates at a much lower age. Second- and third-birth rates are assumed to depend on current age and duration since last previous birth (both as spline functions) and education.

As explained in the introduction, it might be helpful, but not quite correct, to think of education at this high age as a proxy for earlier educational goals and strategies that are exogenous to fertility. In reality, the estimated effects will also capture the reverse causality, but no attempt is made in this study to identify this contribution.

In mathematical terms, the specifications are as follows:

$$
\begin{aligned}
\log \mathrm{h}^{(1)}(\mathrm{a}, \mathbf{x})= & \beta_{0}{ }^{(1)}+\beta_{1}{ }^{(1)} \mathrm{x}_{1}+\beta_{2}{ }^{(1)} \mathrm{x}_{2}+\beta_{3}{ }^{(1)} \mathrm{x}_{3}+\beta_{4}{ }^{(1)} \mathrm{x}_{4}+\boldsymbol{\beta}_{5}{ }^{(1)} \mathbf{S}\left(\mathrm{a}, \mathrm{v}_{1}, \mathrm{v}_{2}, \mathrm{v}_{3}, \mathrm{v}_{4}\right) \\
& +\boldsymbol{\beta}_{6}{ }^{(1)} \mathrm{x}_{1} \mathbf{S}\left(\mathrm{a}, \mathrm{v}_{1}, \mathrm{v}_{2}, \mathrm{v}_{3}, \mathrm{v}_{4}\right)+\boldsymbol{\beta}_{7}{ }^{(1)} \mathrm{x}_{2} \mathbf{S}\left(\mathrm{a}, \mathrm{v}_{1}, \mathrm{v}_{2}, \mathrm{v}_{3}, \mathrm{v}_{4}\right) \\
& +\boldsymbol{\beta}_{8}{ }^{(1)} \mathrm{x}_{3} \mathbf{S}\left(\mathrm{a}, \mathrm{v}_{1}, \mathrm{v}_{2}, \mathrm{v}_{3}, \mathrm{v}_{4}\right) \\
& +\boldsymbol{\beta}_{9}{ }^{(1)} \mathrm{x}_{4} \mathbf{S}\left(\mathrm{a}, \mathrm{v}_{1}, \mathrm{v}_{2}, \mathrm{v}_{3}, \mathrm{v}_{4}\right) \\
\log \mathrm{h}^{(2)}(\mathrm{a}, \mathrm{d}, \mathbf{x})= & \beta_{0}{ }^{(2)}+\beta_{1}{ }^{(2)} \mathrm{x}_{1}+\beta_{2}{ }^{(2)} \mathrm{x}_{2}+\beta_{3}{ }^{(2)} \mathrm{x}_{3}+\beta_{4}{ }^{(2)} \mathrm{x}_{4}+\boldsymbol{\beta}_{5}{ }^{(2)} \mathbf{P}\left(\mathrm{a}, \mathrm{w}_{1}\right) \\
& +\boldsymbol{\beta}_{6}{ }^{(2)} \mathbf{R}\left(\mathrm{d}, \mathrm{z}_{1}, \mathrm{z}_{2}, \mathrm{z}_{3}, \mathrm{z}_{4}\right) \\
\log \mathrm{h}^{(3)}(\mathrm{a}, \mathrm{d}, \mathbf{x})= & \beta_{0}{ }^{(3)}+\beta_{1}{ }^{(3)} \mathrm{x}_{1}+\beta_{2}{ }^{(3)} \mathrm{x}_{2}+\beta_{3}{ }^{\left({ }^{3)}\right.} \mathrm{x}_{3}+\beta_{4}{ }^{(3)} \mathrm{x}_{4}+\boldsymbol{\beta}_{5}{ }^{(3)} \mathbf{P}\left(\mathrm{a}, \mathrm{w}_{1}\right) \\
& +\boldsymbol{\beta}_{6}{ }^{(3)} \mathbf{R}\left(\mathrm{d}, \mathrm{z}_{1}, \mathrm{z}_{2}, \mathrm{z}_{3}, \mathrm{z}_{4}\right)
\end{aligned}
$$

for first (1), second (2) and third (3) births, respectively. In these equations, $\beta_{0}$ is a constant, and $\mathrm{x}_{1}, \mathrm{x}_{2}, \mathrm{x}_{3}$ and $\mathrm{x}_{4}(\mathrm{x}$ in vector notation) are dummies for the educational categories. More precisely, $\mathrm{x}_{1}$ is 1 for 10 years of schooling and otherwise 0 , whereas $\mathrm{x}_{2}=1, \mathrm{x}_{3}=1$ and $\mathrm{x}_{4}=1$ correspond to $11-12$ years, 13-14 years and 15 or more years, respectively. Nine years of education is the arbitrarily chosen reference category. $\beta_{1}$, $\beta_{2}, \beta_{3}$ and $\beta_{4}$ are the corresponding education effects. $\mathbf{S}\left(\mathrm{a}, \mathrm{v}_{1}, \mathrm{v}_{2}, \mathrm{v}_{3}, \mathrm{v}_{4}\right)$ is a piecewise 
linear spline transformation of age, or more precisely age since 15 , with nodes at $\mathrm{v}_{1}=5$ years, $\mathrm{v}_{2}=10$ years, $\mathrm{v}_{3}=15$ years, and $\mathrm{v}_{4}=20$ years. It is defined as a column vector whose transpose is

$\mathbf{S}^{\mathbf{t}}=\quad\left(\min \left[\mathrm{a}, \mathrm{v}_{1}\right], \max \left[0, \min \left[\mathrm{a}-\mathrm{v}_{1}, \mathrm{v}_{2}-\mathrm{v}_{1}\right]\right], \max \left[0, \min \left[\mathrm{a}-\mathrm{v}_{2}, \mathrm{v}_{3}-\mathrm{v}_{2}\right]\right]\right.$, $\left.\max \left[0, \min \left[\mathrm{a}-\mathrm{v}_{3}, \mathrm{v}_{4}-\mathrm{v}_{3}\right]\right], \max \left[0, \mathrm{a}-\mathrm{v}_{4}\right]\right)$.

$\boldsymbol{\beta}_{\mathbf{5}}$ is the corresponding row vector of effects, and $\boldsymbol{\beta}_{\mathbf{6}}, \boldsymbol{\beta}_{\mathbf{7}}, \boldsymbol{\beta}_{\mathbf{8}}$ and $\boldsymbol{\beta}_{\mathbf{9}}$ are interaction effects. For example, for the group with 15 or more years of education, the effect of age is $\boldsymbol{\beta}_{5}+\boldsymbol{\beta}_{9} . \mathbf{P}\left(\mathrm{a}, \mathrm{w}_{1}\right)$ is an age spline with only one node at $\mathrm{w}_{1}=35$ years, and $\mathbf{R}\left(\mathrm{d}, \mathrm{z}_{1}, \mathrm{z}_{2}, \mathrm{z}_{3}, \mathrm{z}_{4}\right)$ is a duration spline with 4 nodes at $\mathrm{z}_{1}=2$ years, $\mathrm{z}_{2}=4$ years, $\mathrm{z}_{3}=6$ years, and $\mathrm{z}_{4}=8$ years.

The effects of high education turn out to be significantly positive (see Table 2), and actually also almost identical to those obtained from a discrete-time model estimated in SAS (not shown). Age and duration profiles seem very reasonable compared to various calculations reported elsewhere (e.g. Brunborg and Kravdal 1986).

The next step is to include an unobserved factor $\delta$ in all three equations and estimate them simultaneously. The specification is as follows:

$$
\begin{aligned}
\log \mathrm{h}^{(1)}(\mathrm{a}, \mathbf{x})= & \beta_{0}{ }^{(1)}+\beta_{1}{ }^{(1)} \mathrm{x}_{1}+\beta_{2}{ }^{(1)} \mathrm{x}_{2}+\beta_{3}{ }^{(1)} \mathrm{x}_{3}+\beta_{4}{ }^{(1)} \mathrm{x}_{4}+\boldsymbol{\beta}_{5}{ }^{(1)} \mathbf{S}\left(\mathrm{a}, \mathrm{v}_{1}, \mathrm{v}_{2}, \mathrm{v}_{3}, \mathrm{v}_{4}\right) \\
& +\boldsymbol{\beta}_{6}{ }^{(1)} \mathrm{x}_{1} \mathbf{S}\left(\mathrm{a}, \mathrm{v}_{1}, \mathrm{v}_{2}, \mathrm{v}_{3}, \mathrm{v}_{4}\right)+\boldsymbol{\beta}_{7}{ }^{(1)} \mathrm{x}_{2} \mathbf{S}\left(\mathrm{a}, \mathrm{v}_{1}, \mathrm{v}_{2}, \mathrm{v}_{3}, \mathrm{v}_{4}\right) \\
& +\boldsymbol{\beta}_{8}{ }^{(1)} \mathrm{x}_{3} \mathbf{S}\left(\mathrm{a}, \mathrm{v}_{1}, \mathrm{v}_{2}, \mathrm{v}_{3}, \mathrm{v}_{4}\right)+\boldsymbol{\beta}_{9}{ }^{(1)} \mathrm{x}_{4} \mathbf{S}\left(\mathrm{a}, \mathrm{v}_{1}, \mathrm{v}_{2}, \mathrm{v}_{3}, \mathrm{v}_{4}\right)+\delta \\
\log \mathrm{h}^{(2)}(\mathrm{a}, \delta, \mathbf{x})= & \beta_{0}{ }^{(2)}+\beta_{1}{ }^{(2)} \mathrm{x}_{1}+\beta_{2}{ }^{(2)} \mathrm{x}_{2}+\beta_{3}{ }^{(2)} \mathrm{x}_{3}+\beta_{4}{ }^{(2)} \mathrm{x}_{4}+\boldsymbol{\beta}_{5}{ }^{(2)} \mathbf{P}\left(\mathrm{a}, \mathrm{w}_{1}\right) \\
& +\boldsymbol{\beta}_{6}{ }^{(2)} \mathbf{R}\left(\delta, \mathrm{z}_{1}, \mathrm{z}_{2}, \mathrm{z}_{3}, \mathrm{z}_{4}\right)+\delta \\
\log \mathrm{h}^{(3)}(\mathrm{a}, \delta, \mathbf{x})= & \beta_{0}{ }^{\left({ }^{(3)}\right.}+\beta_{1}{ }^{(3)} \mathrm{x}_{1}+\beta_{2}{ }^{\left({ }^{(3)}\right.} \mathrm{x}_{2}+\beta_{3}{ }^{(3)} \mathrm{x}_{3}+\beta_{4}{ }^{(3)} \mathrm{x}_{4}+\boldsymbol{\beta}_{5}{ }^{\left({ }^{(3)}\right.} \mathbf{P}\left(\mathrm{a}, \mathrm{w}_{1}\right) \\
& +\boldsymbol{\beta}_{6}{ }^{(3)} \mathbf{R}\left(\delta, \mathrm{z}_{1}, \mathrm{z}_{2}, \mathrm{z}_{3}, \mathrm{z}_{4}\right)+\delta
\end{aligned}
$$

The factor $\delta$ is assumed to be normally distributed with mean 0 and variance $\sigma^{2}$. This distribution is approximated by four support points. Very similar results were obtained with ten support points (not shown). The possibility of including an asymmetric distribution ('finite mixing distribution' in aML terminology) was also checked. The iteration process did not converge with this specification, but when it was automatically terminated, a higher likelihood value had been reached, with model estimates very similar to those obtained with the approximately normal distribution.

The most important result is, of course, that education exerts a significant negative effect on second- and third-birth rates according to this model (Table 2). The effects of 
a college education are quite sharp for second births, whereas third-birth rates are only marginally weaker among women with college education than among others.

Estimates for other cohorts are shown in Table 3. Generally, positive effects of college education on second- and third-birth rates are seen in the separate models (Panel A). For second births, these effects are even more positive for the 1936-40 cohorts than for the 1956-57 cohorts (although differences in second-birth progression ratios are more sharply negative in the former, see Figure 1). The weakest positive effects on second-birth rates are found for women born in the 1940s and early 1950s. For third births, the marked turning point around 1950 is once again seen: Effects of college education are much more positive in the cohorts from the 1950s than for earlier cohorts. Among the latter, the highest effect estimates are for the 1936-40 cohorts, but the differences are not large (compared also with the standard errors of about 0.03).

By contrast, effects of college education are generally negative in the joint models (Panel B). The only exception is for third births in the 1956-57 cohorts, where nonsignificant positive estimates show up. The pattern across cohorts is quite similar to that appearing with the simpler model. The basic message is that the effects of college education are becoming less negative from cohort to cohort, starting from the 1946-50 cohort, although with a drop also from the 1941-45 cohorts in the effects of long college education on third births. For second births, weak negative, or even positive, effects are estimated for the 1936-1940 cohorts. For third births, estimates for the 1936-40 cohorts are less negative than those for women born in the 1940s, but not as weakly negative as for the cohorts from the 1950s.

This pattern from the most complex model is not very different from that appearing in the parity progression ratios. For example, the quite sharp turning point in 1950 for third births appears very clearly. However, one exception to the similarity is that the effect of a short college education in the third-birth model for the 1936-40 cohorts is almost equal to the corresponding effect for the 1951-55 cohorts. Nevertheless, the differences in third-birth progression ratios are much more pronounced in the 1936-40 cohorts. Moreover, the effect of long college education for third births is less negative for the 1936-40 cohorts than for the 1946-50 cohorts, whereas the pattern in the corresponding parity progression ratios is opposite. The sharper negative age effect in the 1936-40 cohorts (not shown) must be one explanation for this. 
Table 2: $\quad$ Estimated effects (with standard deviation) of age, duration since last previous birth, and educational level at age 40-44 on first-, second-, and third-birth rates, based on data from the Norwegian Population Register for women born 1951-55.

\begin{tabular}{|c|c|c|c|c|}
\hline & \multicolumn{2}{|l|}{$\begin{array}{l}\text { Birth rates modelled } \\
\text { separately for each parity }\end{array}$} & \multicolumn{2}{|c|}{$\begin{array}{l}\text { Birth rates modelled jointly, with common } \\
\text { unobserved factor }\end{array}$} \\
\hline \multicolumn{5}{|l|}{ First birth } \\
\hline Constant term & $-6.0559^{\star \star \star}$ & $(0.0284)$ & $-6.5676^{\star \star \star}$ & $(0.0322)$ \\
\hline \multicolumn{5}{|l|}{ Age spline } \\
\hline $15-20$ years & $0.0399^{* \star *}$ & $(0.0006)$ & $0.0500^{* * *}$ & $(0.0007)$ \\
\hline $20-25$ years & $-0.0139^{\star \star \star}$ & $(0.0005)$ & $-0.0049^{\star \star *}$ & $(0.0005)$ \\
\hline $25-30$ years & $-0.0081^{\star \star \star}$ & $(0.0008)$ & $-0.0062^{* \star *}$ & $(0.0008)$ \\
\hline $30-35$ years & $-0.0143^{* \star \star}$ & $(0.0014)$ & $-0.0132^{\star \star \star}$ & $(0.0014)$ \\
\hline $35-40$ years & $-0.1525^{\star \star \star}$ & $(0.0036)$ & $-0.0149^{\star \star \star}$ & $(0.0036)$ \\
\hline \multicolumn{5}{|c|}{ Educational level } \\
\hline 9 years $^{1}$ & 0 & & 0 & \\
\hline 10 years & $-1.1971^{\star \star \star}$ & $(0.0405)$ & $-1.1265^{\star \star \star}$ & $(0.0421)$ \\
\hline $11-12$ years & $-1.2060^{\star \star \star}$ & $(0.0512)$ & $-1.0960^{\star \star *}$ & $(0.0528)$ \\
\hline $13-14$ years & $-2.9264^{\star \star \star}$ & $(0.1056)$ & $-2.6764^{\star \star \star}$ & $(0.1056)$ \\
\hline 15- years & $-2.3067^{\star \star \star}$ & $(0.0850)$ & $-2.0945^{\star \star \star}$ & $(0.0858)$ \\
\hline \multicolumn{5}{|c|}{ Additional age spline } \\
\hline $15-20$ years & $0.0122^{\star \star \star}$ & $(0.0008)$ & $0.0076^{* \star *}$ & $(0.0008)$ \\
\hline $20-25$ years & $0.0120^{* \star \star}$ & $(0.0005)$ & $0.0112^{* \star *}$ & $(0.0006)$ \\
\hline $25-30$ years & -0.0006 & $(0.0009)$ & $0.0024^{\star \star}$ & $(0.0009)$ \\
\hline $30-35$ years & 0.0026 & $(0.0016)$ & $0.0028^{*}$ & $(0.0016)$ \\
\hline $35-40$ years & -0.0014 & $(0.0041)$ & -0.0008 & $(0.0041)$ \\
\hline \multicolumn{5}{|c|}{ Additional age spline } \\
\hline \multicolumn{5}{|c|}{ for $11-12$ years of education } \\
\hline $15-20$ years & $0.0076^{\star \star \star}$ & $(0.0010)$ & 0.0017 & $(0.0010)$ \\
\hline $20-25$ years & $0.0154^{\star \star \star}$ & $(0.0006)$ & $0.0134^{\star \star *}$ & $(0.0006)$ \\
\hline $25-30$ years & $0.0030^{\star \star \star}$ & $(0.0010)$ & $0.0066^{* \star *}$ & $(0.0010)$ \\
\hline $30-35$ years & $0.0032^{*}$ & $(0.0017)$ & $0.0040^{* *}$ & $(0.0017)$ \\
\hline $35-40$ years & -0.0007 & $(0.0044)$ & 0.0000 & $(0.0043)$ \\
\hline \multicolumn{5}{|c|}{ Additional age spline } \\
\hline \multicolumn{5}{|c|}{ For $13-14$ years of education } \\
\hline $15-20$ years & $0.0129^{\star \star \star}$ & $(0.0020)$ & 0.0019 & $(0.0020)$ \\
\hline $20-25$ years & $0.0395^{\star \star \star}$ & $(0.0007)$ & $0.0352^{\star \star \star}$ & $(0.0007)$ \\
\hline $25-30$ years & $0.0057^{\star \star \star}$ & $(0.0009)$ & $0.0106^{\star \star \star}$ & $(0.0010)$ \\
\hline 30-35 years & $0.0045^{\star \star \star}$ & $(0.0016)$ & $0.0075^{\star \star \star}$ & $(0.0016)$ \\
\hline $35-40$ years & 0.0017 & $(0.0042)$ & 0.0028 & $(0.0042)$ \\
\hline \multicolumn{5}{|c|}{ Additional age spline } \\
\hline \multicolumn{5}{|c|}{ For 15 - years of education } \\
\hline $15-20$ years & $0.0053^{* \star \star}$ & $(0.0016)$ & $-0.0043^{\star \star \star}$ & $(0.0017)$ \\
\hline $20-25$ years & $0.0328^{\star \star \star}$ & $(0.0007)$ & $0.0275^{\star \star \star}$ & $(0.0007)$ \\
\hline $25-30$ years & $0.0091^{\star \star \star}$ & $(0.0009)$ & $0.0131^{\star \star \star}$ & $(0.0009)$ \\
\hline $30-35$ years & $0.0057^{\star \star \star}$ & $(0.0016)$ & $0.0088^{* * *}$ & $(0.0016)$ \\
\hline $35-40$ years & 0.0021 & $(0.0040)$ & 0.0039 & $(0.0040)$ \\
\hline
\end{tabular}


Demographic Research - Volume 5, Article 6

Table 2: $\quad$ Continued

\begin{tabular}{|c|c|c|c|c|}
\hline & $\begin{array}{l}\text { Birth rates modelled } \\
\text { separately for each parity }\end{array}$ & & $\begin{array}{l}\text { Birth rates modellec } \\
\text { unobserved factor }\end{array}$ & ommon \\
\hline \multicolumn{5}{|l|}{ Second birth } \\
\hline Constant term & $-7.0816^{* * *}$ & $(0.0331)$ & $-9.1157^{\star \star *}$ & $(0.0628)$ \\
\hline \multicolumn{5}{|l|}{ Duration spline } \\
\hline $0-24$ months & $0.1538^{* * *}$ & $(0.0013)$ & $0.1547^{\star \star *}$ & $(0.0013)$ \\
\hline $25-48$ months & $0.0055^{\star * *}$ & $(0.0005)$ & $0.0114^{\star * *}$ & $(0.0005)$ \\
\hline 49-72 months & $-0.0263^{\star \star *}$ & $(0.0006)$ & $-0.0252^{* * *}$ & $(0.0006)$ \\
\hline 73-96 months & $-0.0210^{* * *}$ & $(0.0008)$ & $-0.0228^{\star * *}$ & $(0.0008)$ \\
\hline 96- months & $-0.0140^{* \star *}$ & $(0.0004)$ & $-0.0177^{\star * *}$ & $(0.0004)$ \\
\hline \multicolumn{5}{|l|}{ Age spline } \\
\hline $15-35$ years & $-0.0010^{* * *}$ & $(0.0001)$ & $0.0055^{\star * *}$ & $(0.0002)$ \\
\hline 35- years & $-0.0145^{\star * *}$ & $(0.0005)$ & $-0.0131^{* * *}$ & $(0.0005)$ \\
\hline \multicolumn{5}{|l|}{ Educational level } \\
\hline 9 years $^{1}$ & 0 & & 0 & \\
\hline 10 years & $0.0230^{\star * *}$ & $(0.0086)$ & $-0.1428^{* * *}$ & $(0.0112)$ \\
\hline $11-12$ years & 0.0092 & $(0.0101)$ & $-0.2210^{\star * *}$ & $(0.0135)$ \\
\hline $13-14$ years & $0.1645^{\star * *}$ & $(0.0118)$ & $-0.2697^{* * *}$ & $(0.0182)$ \\
\hline 15- years & $0.1217^{* * *}$ & $(0.0113)$ & $-0.3350^{\text {*** }}$ & $(0.0179)$ \\
\hline \multicolumn{5}{|l|}{$\underline{\text { Third birth }}$} \\
\hline Constant term & $-6.7505^{* * *}$ & $(0.0635)$ & $-9.6459 * * *$ & $(0.0892)$ \\
\hline \multicolumn{5}{|l|}{ Duration spline } \\
\hline $0-24$ months & $0.1317^{* \star *}$ & $(0.0024)$ & $0.1253^{\star \star *}$ & $(0.0024)$ \\
\hline $25-48$ months & $-0.0014^{*}$ & $(0.0008)$ & $-0.0066^{* * *}$ & $(0.0009)$ \\
\hline 49-72 months & $-0.0040^{\star \star *}$ & $(0.0009)$ & $-0.0062^{\star \star *}$ & $(0.0008)$ \\
\hline 73-96 months & $-0.0156^{* * *}$ & $(0.0010)$ & $-0.0214^{* * *}$ & $(0.0010)$ \\
\hline 96- months & $-0.0090^{* * *}$ & $(0.0004)$ & $-0.0152^{* * *}$ & $(0.0005)$ \\
\hline \multicolumn{5}{|l|}{ Age spline } \\
\hline $15-35$ years & $-0.0041^{* * *}$ & $(0.0001)$ & $0.0042^{* * *}$ & $(0.0002)$ \\
\hline 35- years & $-0.0159^{\star * *}$ & $(0.0006)$ & $-0.0112^{\star * *}$ & $(0.0006)$ \\
\hline \multicolumn{5}{|l|}{ Educational level } \\
\hline 9 years $^{1}$ & 0 & & 0 & \\
\hline 10 years & $-0.0386^{* * *}$ & $(0.0138)$ & $-0.2079^{\star * *}$ & $(0.0159)$ \\
\hline $11-12$ years & -0.0076 & $(0.0163)$ & $-0.2396^{* * *}$ & $(0.0191)$ \\
\hline 13-14 years & $0.3822^{\star \star \star}$ & $(0.0185)$ & $-0.0647^{\star \star *}$ & $(0.0235)$ \\
\hline 15- years & $0.3701^{* * *}$ & $(0.0178)$ & $-0.0849^{\star * *}$ & $(0.0231)$ \\
\hline \multicolumn{5}{|l|}{ Standard deviation of } \\
\hline Log likelihood & & -1541407.1 & & 126.3 \\
\hline
\end{tabular}

Reference category

* $\quad \mathrm{p}<0.10$

** $\quad p<0.05$

*** $p<0.01$ 
Table 3: $\quad$ Estimated effects of educational level at age 40-44 on second-and thirdbirth rates, based on data from the Norwegian Population Register for women born 1936-57, by cohort. ${ }^{1}$

\begin{tabular}{|c|c|c|c|c|c|}
\hline \multicolumn{6}{|c|}{ Panel A: Birth rates modelled separately } \\
\hline & $1936-40$ & $1941-45$ & $1946-50$ & $1951-55$ & $1956-57$ \\
\hline \multicolumn{6}{|l|}{ Second birth } \\
\hline \multicolumn{6}{|c|}{$\overline{\text { Educational level }}$} \\
\hline 9 years $^{2}$ & 0 & 0 & 0 & 0 & 0 \\
\hline 10 years & $0.12^{\star \star *}$ & $0.03^{\star \star \star}$ & -0.01 & $0.02^{\star * *}$ & $0.08^{\star \star *}$ \\
\hline $11-12$ years & $0.11^{\star \star \star}$ & -0.02 & $-0.04^{*}$ & 0.01 & $0.07^{\star * *}$ \\
\hline $13-14$ years & $0.34^{* * *}$ & $0.17^{\star \star \star}$ & $0.09^{* * *}$ & $0.16^{\star * *}$ & $0.27^{\star \star *}$ \\
\hline 15- years & $0.26^{* * *}$ & $0.09^{* * *}$ & 0.02 & $0.12^{* \star *}$ & $0.23^{* * *}$ \\
\hline \multicolumn{6}{|l|}{ Third birth } \\
\hline \multicolumn{6}{|c|}{ Educational level } \\
\hline 9 years $^{2}$ & 0 & 0 & 0 & 0 & 0 \\
\hline 10 years & 0.01 & $-0.06^{* \star *}$ & $-0.12^{* * *}$ & $-0.04^{* * *}$ & 0.01 \\
\hline $11-12$ years & 0.02 & $-0.14^{\star * *}$ & $-0.12^{\star * *}$ & -0.01 & 0.03 \\
\hline $13-14$ years & $0.27^{\star \star \star}$ & $0.21^{\star \star \star}$ & $0.23^{\star * *}$ & $0.38^{* \star *}$ & $0.43^{\star \star \star}$ \\
\hline 15- years & $0.20^{\star \star \star}$ & $0.06^{\star \star \star}$ & $0.19^{* \star *}$ & $0.37^{* * *}$ & $0.44^{\star \star *}$ \\
\hline Log likelihood & -1131109.6 & -1353085.1 & -1586778.3 & -1541407.1 & -642489.9 \\
\hline
\end{tabular}

Panel B: Birth rates modelled jointly, including the first-birth rate

\begin{tabular}{|c|c|c|c|c|c|}
\hline & $1936-40$ & $1941-45$ & $1946-50$ & $1951-55$ & $1956-57$ \\
\hline \multicolumn{6}{|l|}{ Second birth } \\
\hline \multicolumn{6}{|c|}{ Educational level } \\
\hline 9 years $^{2}$ & 0 & 0 & 0 & 0 & 0 \\
\hline 10 years & $0.03^{\star \star \star}$ & $-0.08^{\star * \star}$ & $-0.17^{\star \star \star}$ & $-0.14^{\star \star *}$ & $-0.05^{\star * *}$ \\
\hline $11-12$ years & $-0.08^{\star * \star}$ & $-0.26^{\star \star *}$ & $-0.30^{\star * *}$ & $-0.22^{\star * *}$ & $-0.15^{\star \star *}$ \\
\hline $13-14$ years & $0.09^{\star \star *}$ & $-0.18^{\star \star \star}$ & $-0.35^{\star * *}$ & $-0.27^{\star \star \star}$ & $-0.10^{\star \star \star}$ \\
\hline 15- years & $-0.08^{* * *}$ & $-0.34^{* * *}$ & $-0.50^{* * *}$ & $-0.34^{\star * *}$ & $-0.16^{\star \star *}$ \\
\hline \multicolumn{6}{|l|}{ Third birth } \\
\hline \multicolumn{6}{|c|}{ Educational level } \\
\hline 9 years $^{2}$ & 0 & 0 & 0 & 0 & 0 \\
\hline 10 years & $-0.11^{* * *}$ & $-0.22^{* * *}$ & $-0.32^{* * *}$ & $-0.21^{\star * *}$ & $-0.13^{* * *}$ \\
\hline $11-12$ years & $-0.22^{\star \star *}$ & $-0.45^{\star \star \star}$ & $-0.44^{\star \star *}$ & $-0.24^{\star \star *}$ & $-0.20^{\star \star \star}$ \\
\hline $13-14$ years & $-0.05^{* *}$ & $-0.22^{\star \star \star}$ & $-0.27^{\star * *}$ & $-0.06^{\star * *}$ & 0.04 \\
\hline $15-$ years & $-0.21^{* \star *}$ & $-0.42^{\star \star *}$ & $-0.34^{\star * *}$ & $-0.08^{\star * *}$ & 0.05 \\
\hline \multicolumn{6}{|c|}{ Standard deviation of } \\
\hline unobserved & $0.72^{* \star \star}$ & $0.76^{\star \star *}$ & $0.81^{* \star *}$ & $0.79^{\star \star *}$ & $0.79^{\star \star \star}$ \\
\hline
\end{tabular}

$\begin{array}{llllll}\text { Log likelihood } & -1130166.2 & -1351712.4 & -1584971.8 & -1540126.3 & -642007.7\end{array}$

1 Effects of age, duration and the constant term are shown in Table 2 for the 1951-55 cohort, and not shown anywhere for the other cohorts

2 Reference category

${ }^{\star} p<0.10 ;{ }^{* *} p<0.05 ;{ }^{* \star *} p<0.01$ 


\section{Simulations}

The properties of these joint models are now illustrated by simulation, on the basis of estimates for the 1951-1955 cohorts. The simulation procedure is as follows: A sample of 50000 women is selected for each of the five educational levels. (Experimentation proved this to be a sufficiently large sample size.) A value of $\delta$ is first drawn for each woman, in accordance with the estimate of its variance. Subsequently, a birth rate is predicted for each woman for each month from age 15 to age 40, on the basis of parity, age and duration at that time and the corresponding effect estimates. This predicted rate is then transformed into a one-month birth probability. If a number drawn from a uniform $[0,1]$ distribution is lower than this predicted probability, a birth is ascribed to the woman this month. This procedure yields simulated birth histories for each of the 50000 women in each educational group, from which various summary measures can be calculated or models estimated. On the whole, parity distributions, parity progression ratios and completed fertility obtained from this simulation sample accord well with those reported in Table 1. A few figures are shown in Table 4.

Table 4: $\quad$ Third-birth progression ratios (in \%) calculated from real data and simulation samples, according to different simulation models based on the estimates for the 1951-55 cohorts

\begin{tabular}{|c|c|c|c|c|}
\hline & \multicolumn{3}{|c|}{ FROM SIMULATION SAMPLE } & \multirow{2}{*}{$\begin{array}{l}\text { FROM REAL } \\
\underline{\text { DATA }}\end{array}$} \\
\hline & $\begin{array}{l}\text { Based on } \\
\text { estimates from } \\
\text { joint model shown } \\
\text { in Table } 2\end{array}$ & $\begin{array}{l}\text { Based on } \\
\text { estimates from } \\
\text { joint model shown } \\
\text { in Table } 2 \text { but } \\
\text { with unobserved } \\
\text { factor set to zero } \\
\text { after first birth }\end{array}$ & $\begin{array}{l}\text { Based on } \\
\text { estimates from } \\
\text { joint model shown } \\
\text { in Table } 2 \text { but } \\
\text { with unobserved } \\
\text { factor and } \\
\text { education effect } \\
\text { set to zero after } \\
\text { first birth }\end{array}$ & \\
\hline \multicolumn{5}{|c|}{ Educational level } \\
\hline 9 years & 42.8 & 34.3 & 34.3 & 45.0 \\
\hline 10 years & 38.2 & 28.2 & 33.5 & 39.8 \\
\hline $11-12$ years & 36.7 & 27.0 & 32.9 & 38.8 \\
\hline $13-14$ years & 41.0 & 29.3 & 31.4 & 41.7 \\
\hline $15-$ years & 40.5 & 28.0 & 30.9 & 41.4 \\
\hline
\end{tabular}


The slightly lower third-birth progression ratios for the better-educated than for the poorly educated which are simulated (Table 4, column 1), and which also appear (although slightly more pronounced) in the real data (Table 4, column 4), are partly a spill-over from the higher age at first birth. This can be seen by setting both the effect of education and the unobserved factor to zero for transitions beyond parity one in the simulation. To elaborate on this, the average age at first birth (among women who ever become mothers) is about five years higher for the college educated than for those with only compulsory education. If second-birth rates are dependent on only age and duration, there will be almost the same difference in the age at second birth. This must have consequences for the third-birth progression ratio, if we still assume that the higher-order rates are dependent on age and duration exclusively. As an illustration, the proportions of two-child mothers at different ages who have a third child within one year is calculated from the simulation sample for three groups: i) women with only compulsory education who have their second child at age 25 (according to the simulations), which is close to the average for this educational group, ii) women with only compulsory education who have their second child at the relatively high age of 30 , which is close to the average for those with a long college education, and iii) women with long college education who display 'mainstream' behaviour by having their second child at age 30. The results are shown in Figure 2a. The proportion of two-child mothers who ever have a third child, which corresponds roughly to the area under the curve, is higher for those who have their second birth at age 25 than for those who have it at age 30. Given the assumptions in these simulations, the third-birth probabilities are, of course, virtually the same for all categories of women who have their second child at age 30 (or any other age), regardless of education. (The small differences, seen in Figure $2 \mathrm{a}$ between the two groups of women who bear a child at age 30, merely reflect the stochastic nature of the simulations.) However, the differences between these women who have their second birth five years apart are not large, only 1.7 percentage points (not shown). This is because the rates at early durations actually are highest for women who have their second child at age 30, as a result of the positive age effect up to 35 (as opposed to the negative corresponding effect in the separate model; see Table 2). At longer durations, however, the women who start at age 30 enter ages when fertility is very low. The proportion who ever have a third child drops very sharply as the age at second birth reaches the mid- and late-30s, but after all, the proportion who have their second child at these high ages is not very large even among the better-educated. This is the reason why the gap in the third-birth progression ratios between the 50000 women with low education and those with long college education (i.e. all ages at second birth pooled together) is only 3.4 percentage points (Table 4 , column 3 ). 
When the quite weak negative effect of education is also taken into account in the simulation, a lower proportion proceeding to parity three is simulated for the college educated (Figure 2b). For example, the difference in this proportion between women with only compulsory education who have their second child at age 25 and those with a long college education who have it at age 30 is 6.2 percentage points (not shown). When all women in these two educational groups are considered, regardless of age at second birth, the difference becomes 6.3 percentage points (Table 4, column 2).

When also the effect of the unobserved factor is included, large differences emerge between women who have their second child at age 25 and those who have it at age 30, given educational level, and vice versa. This is seen in the curves in Figure 2c, which actually also show a pattern quite similar to that obtained with real data (Figure $2 \mathrm{~d}$ ). The reason for this pattern is that women with low education who have their second child at age 25 have an average score a little higher than 0 on the unobserved factor, whereas those who have their second child at age 30 , about five years beyond the average for this educational category, score lower (according to the simulation; not shown). By contrast, better-educated women who have their second child at age 30 have a score more markedly higher than 0 . The proportion eventually having a third child among women with long college education who have their second child at age 30 is 0.6 percentage points higher than that for women with only compulsory education who have it at age 25 (according to the simulation; not shown). In comparison, the corresponding proportion for women with compulsory education who are 'late starters' (i.e. have their second child at age 30) is 9.9 percentage points lower. On average, the better-educated two-child mothers have a higher score on the unobserved factor than the poorly educated, so when all ages at second birth are considered, a difference of 2.3 percentage points appears between those with compulsory education and those with a long college education (Table 4, column 1). This accords quite well with the gap of 3.6 percentage points in the real data (Table 4, column 4).

It might be added that, when separate third-birth models are estimated from this simulation sample, the effects (not shown) are almost identical to those shown in Table 2 on the basis of real data. In other words, when a joint model with a negative education effect and an unobserved factor as specified above is used to simulate a sample, a separate birth rate modelling from this sample yields a positive education effect. 
Figure 2: $\quad$ Proportion of two-child mothers who have a third child within one year, by age, for three different combinations of age at second birth and educational level, calculated from a sample simulated according to three different sets of effect parameters, or from real data

a)

Simulation based on estimates from joint model shown in Table 2, except that the unobserved factor and the education effect are set to zero after first birth

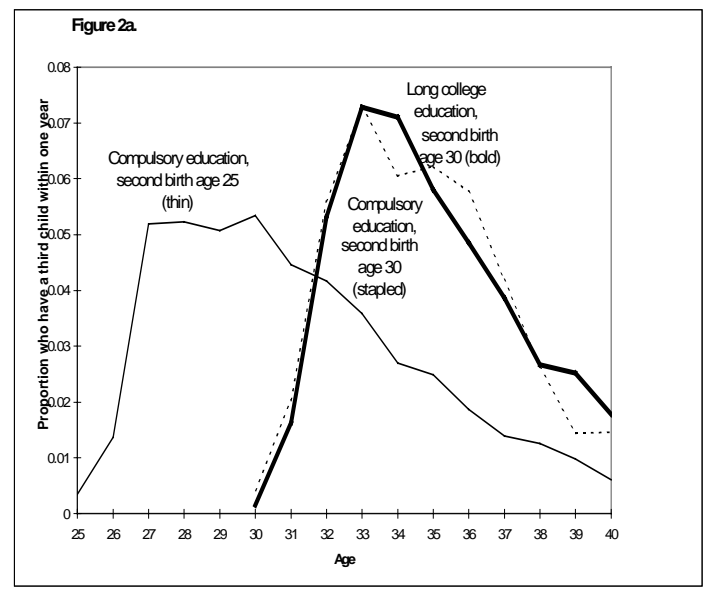

b)

Simulation based on estimates from joint model shown in Table 2, except that the unobserved factor is set to zero after first birth.

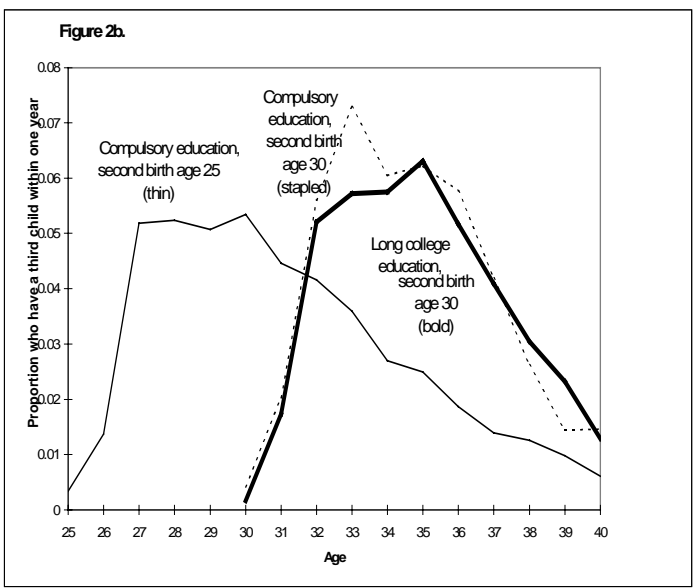


Figure 2: $\quad$ Continued

c) Simulation based on estimates from joint model shown in Table 2

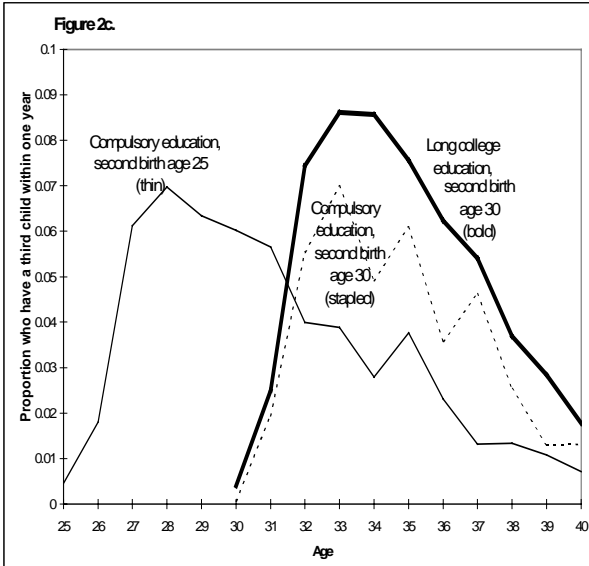

d) Real data

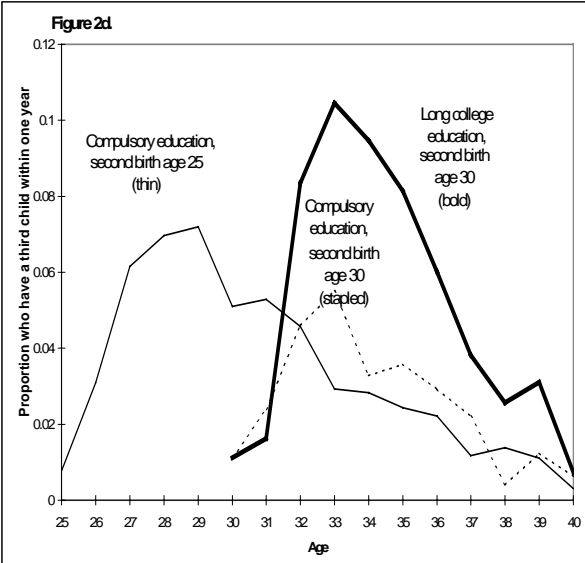




\section{Models Estimated from Survey Data}

Models are also estimated on the basis of survey data for the 1945 cohort, in order to check the importance of current educational level and enrollment, rather than the level at age 40 . Because this is a much smaller sample, women with 11 or more years of education are pooled together.

In parallel with the approach for register data, models are first estimated separately for first, second and third births. The first-birth rate is assumed to depend on age (specified as a spline function), current educational level and activity, and an interaction between age and educational level. For simplicity, the latter is specified as an additional effect of education when age is higher than 25. Such interactions have been seen in previous studies (Kravdal 1994). Second- and third-birth rates are assumed to depend on age and duration since last previous birth (both specified as splines) and current educational level and activity. The specifications are otherwise as with the register data, so it should be unnecessary to write the equations.

A generally negative effect is estimated for enrollment, as expected (Table 5). Moreover, the educational level has a positive effect on second births and no effect on third births. (This is not strongly inconsistent with the results from the register-based model for the 1941-45 cohort, as the categorization of education is different. Registerbased models for second birth for these cohorts give a significant positive effect of 11 or more years of education, whereas a positive effect of borderline significance appears for third births). For first births, the main effect of educational level is negative, but there is a significant interaction. At ages above 25, first-birth rates are highest for women with at least 11 years of schooling. If the interaction is excluded, a non-significant negative effect of education beyond the compulsory level is estimated. This lack of a clear negative 'overall' effect of educational level fits well with previous conclusions both from Norway and Germany that the delay of parenthood is primarily due to a long period of enrollment (perhaps because of norms restricting childbearing at this stage, or because a birth may be thought to inhibit the completion of the education and thus give rise to a long-term economic penalty).

The next step is to include an unobserved factor with influence on all transitions. This removes the positive effect of the highest educational level for ages above 25 , and gives a significantly negative 'overall' effect of educational level on first birth rates. Besides the effect of educational level on second birth rates is no longer positive (but it is not significantly negative either, as in the register data). There are indications of negative effects for third births.

It is worth noting that similar interaction patterns appear in the register data for the 1941-45 cohorts (not shown). For example, according to the separate model for first 
Table 5: $\quad$ Estimated effects of current educational level and enrollment on first-, second-, and third-birth rates, based on data from the Norwegian Family and Occupation Survey of 1988 for women born $1945^{1}$

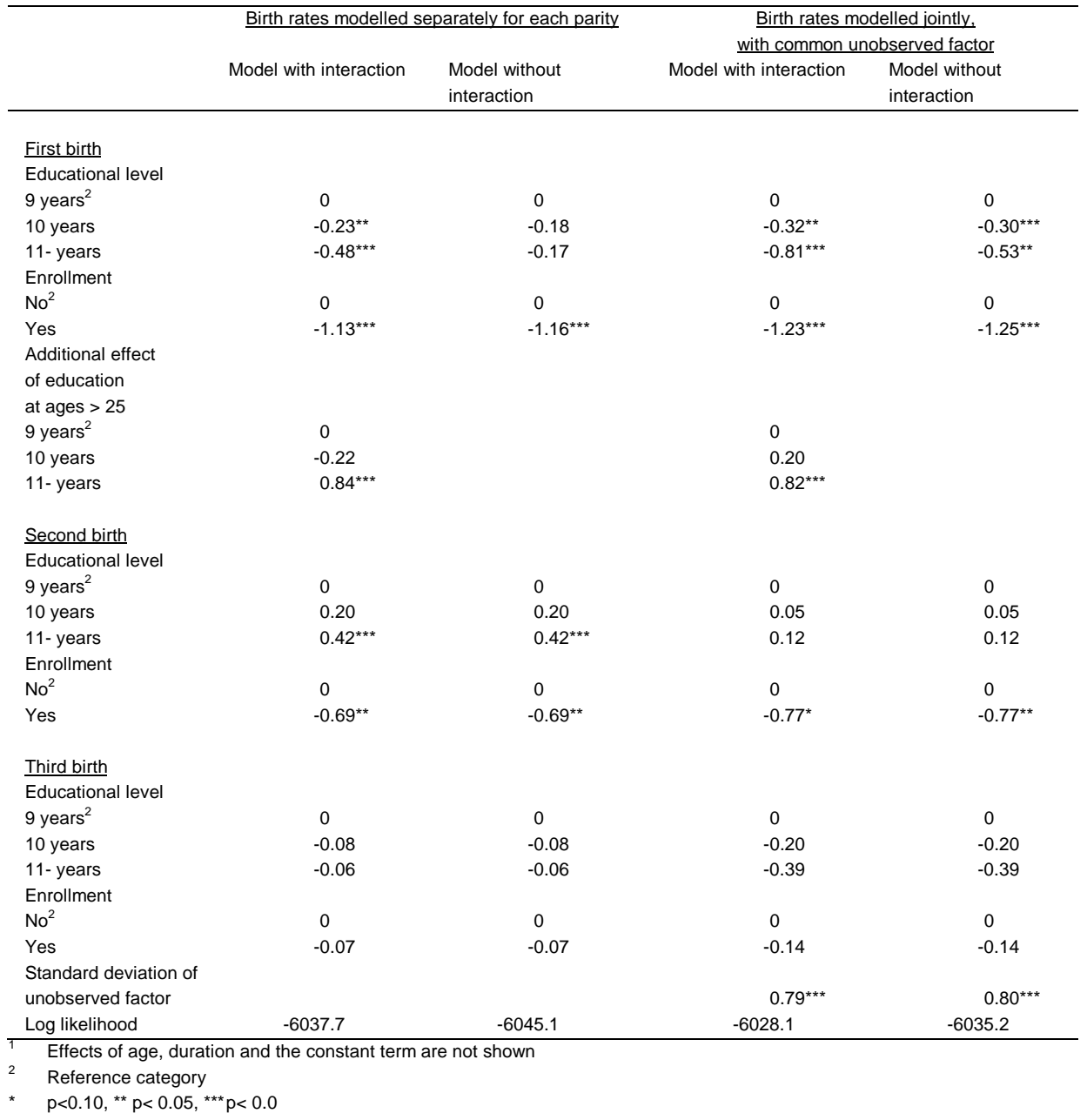


births, the predicted rate at age 30 for women with long college education is higher than that for women with only compulsory education. According to the joint model, however, there is only a minor difference, and in the opposite direction, between the two groups at this age. A reduction, but not elimination, of the difference is seen also for women with 13-14 years of education. By contrast, education has a positive effect on third birth rates at age 30 in both models for the 1951-55 cohorts (as can be seen from the age-education interaction effects and the main effects of education in Table 2).

\section{Summary and Conclusions}

In this register-based analysis of the birth cohorts 1936-57, separate models for thirdbirth rates reveal significant positive effects of college education, net of age and duration since previous birth. The effects are sharper for the cohorts from the 1950s, who had their second child in the mid-1970s or later, than for those born earlier. A similar pattern appears in the second-birth rates. However, when first-, second- and third-birth rates are modelled jointly, and an unobserved factor with a persistent influence is included, the effects of high education are no longer positive, but (with one exception) significantly negative.

For third births, the conclusion is that the strongest negative effects are seen in the cohorts from the 1940s, whereas those born 1951-55 display much weaker effects, and a non-significant positive effect is seen for those born in 1956-57. This accords well with the ideas that opportunity costs of childbearing to a larger extent are substituted with much less varying child care costs in the youngest cohorts, or that the poorly educated perhaps have been relatively slow in adopting modern contraception or experiencing various fertility-reducing changes in norms and preferences.

Another possibility, not mentioned above, is that the selection into education may have changed over time. Only $6 \%$ attained the level corresponding to at least a Bachelor's degree in the 1941-45 cohorts, as compared to $17 \%$ in the 1956-57 cohorts (Table 1). In the younger cohorts, a larger proportion of the college educated probably have parents with little education (and partly as a result of policies explicitly meant to make educational opportunities less dependent on social background), which might be positively linked with fertility, for reasons not discussed here. It is also possible that the implications of having a high education, for example for earnings potentials, have changed as it has become more common. Similarly, having only a compulsory education may have another meaning for the 1956-57 cohorts, where only $13 \%$ of the women were in this category, than for the 1941-45 cohorts, where the proportion was 30\%. In future studies, this issue might be addressed by including various characteristics of the family of origin in the fertility models, by including relative education, or by comparing 
fertility of siblings. It might also be helpful to model educational careers and fertility simultaneously.

The cohorts from the late 1930s do not fit quite nicely into this smooth drift towards less negative net effects of education. In fact, more clearly negative effects are seen in the cohorts from the 1940s than for the older cohorts. This makes sense from the diffusion perspective underlying some of the foregoing discussion of more recent changes (see introduction): A period with modest differences between groups is followed by a larger gap as changes take place first among the 'avant-gardists', and the gap narrows again when the others follow suit. Similarly, also the opportunity-cost argument presented above can be extended backwards in a plausible way, by considering the development as a three-stage process: First, fertility is relatively high and educational gradients weak when women generally leave the labour force when they become mothers, or even at marriage, and do not consider paid work an alternative to further childbearing. Second, increased demand for female labour and various other socioeconomic and ideational changes make more and more women take the opportunity costs into account, which reduces fertility and creates larger educational differentials (see Kravdal (1992b) for an assessment of the opportunity costs in Norway). Third, almost everyone recognizes gainful employment as an alternative, but because of various family- and labour-policy reforms and a better access to and presumably accept for purchased child care, it becomes easier to resume market work quite shortly after birth, although at the expense of higher child care costs. The sum of opportunity and direct costs will typically show a downward trend, which will contribute to push fertility up. Besides, educational gradients may weaken when the price of child care, which is less wage dependent, becomes a more important ingredient of the total costs. It might be added that, at this third stage, differences in employment rates between women in different sub-populations (or countries) are not primarily an indication of differences in the tendency to take lost income into account (because they all do that), but an indication of different possibilities for resuming employment shortly after birth, and thus in childbearing costs. In other words, high employment may well go hand in hand with high fertility (see Hoem and Hoem (1989) and Kravdal (1992c) for analyses of a similar relationship at an individual level, and Brewster and Rindfuss (2000) for a more general discussion).

The story is very similar for second births. Net education effects reach the same size as for third births for some cohorts, but give rise to only a few percentage point lower second-birth progression ratios among the college educated than those with only compulsory education. The main difference compared to the third births is that effects of college education are less clearly negative for the 1936-40 cohorts than for all other cohorts studied, or in fact even positive. (However, differences in the second-birth progression ratios are nevertheless sharper for the 1936-40 cohorts than for the 1956-57 
cohorts). Besides, the most negative effects of education on second births are seen for the 1946-50 cohorts, whereas there is little difference between education effects on third births for the 1941-45 and 1946-50 cohorts. This pattern may to some extent signal that changes, not surprisingly, are period rather than cohort driven (which is further supported by the development in fourth-birth progression ratios).

Another important result of this study is that a positive effect of high education is estimated for first-birth rates above age 25 when these rates are modelled separately on the basis of a survey sample for the 1945 cohort. However, also this positive effect disappears in a joint model for first, second and third births. (In support of this, a similar pattern is seen in the register-based models, using the educational level achieved at age 40.)

Other specifications of the unobserved factor might have given other effects of education and an even better fit to the data. Moreover, any model with unobserved heterogeneity could always be matched by a model without unobserved heterogeneity by fine-tuning age and duration profiles (i.e. using a larger number of break points (nodes in the spline)) in the latter and allowing complex interactions with education. However, the joint model estimated here at least fits the data better than the simple separate models, and the parameters are interpretable, which would be harder to claim if more complex separate models were specified. To conclude, there seems to be little reason to speculate about possible reasons for positive education effects. The observed pattern is more consistent with the simple idea that people are influenced by a kind of 'fertilityproneness' throughout their reproductive careers, and that various factors associated with a high education still contribute to push fertility down, although less markedly than previously (at least when comparing with the cohorts from the 1940s).

In addition to being of importance from a descriptive, and even theoretical, point of view, these results illustrate that the joint modelling is more than a futile methodological snobbery. In this particular case, the estimates from separate models are indeed misleading.

To conclude with a piece of description, the estimates suggest the following pattern for the youngest Norwegian birth cohorts who have now completed childbearing: Women who end up with a higher education have their first child later than those with only compulsory education, and a larger proportion remain childless. In principle, this could be due to the lower birth rate during school enrollment, a lower rate because of the higher educational level itself, or a reverse causation. The latter is not checked here, but a model for an older cohort suggests effects of both enrollment and educational level (the former being very sharp). Beyond parity one, education has a modest impact on progression ratios. Those who end up with a college degree (and most of whom had that level already when they became mothers) show just as high second-birth progression ratios as those with compulsory education, or even higher. Their third-birth progression 
ratios are a few percentage points lower, and the gap somewhat larger for fourth births. Three mechanisms operating in different directions produce these moderate differences. First, there is a weak spill-over effect due to the later entry into motherhood. For example, the probability that a two-child mother will ever have a third child declines quite sharply as her age at second birth exceeds about age 30, and a larger proportion of the better-educated women are in this category. Second, a higher education reduces third-birth rates slightly, given age. However, this is set off against the counteracting unobserved heterogeneity effects: When all ages at second birth are considered, the score on an unobserved fertility-stimulating factor is slightly higher for the bettereducated than for the poorly educated (but at any given age at second birth, the score is substantially higher for the former).

\section{Acknowledgements}

Comments from David Guilkey, Stan Panis and two anonymous referees are greatly acknowledged. Financial support to establish the data was provided by the Norwegian Research Council. This work was strongly inspired by Britta Hoem's many clever efforts to uncover education effects, as reported for example in her 1996 research note. I was saddened by her premature death and will greatly miss the discussions with her, the possibility of reading new insightful scientific contributions, and her extraordinary hospitality, warmth and friendliness. 


\section{References}

Blake, J. (1968). “Are babies consumer durables?” Population Studies 22: 1-25.

Blossfeld, H.-P. and J. Huinink. (1991). "Human capital investments or norms of role transition? How women's schooling and career affect the process of family formation." American Journal of Sociology 97: 143-168.

Brewster, K.L. and R.R. Rindfuss. (2000). "Fertility and women's employment in industrialized nations." Annual Review of Sociology 26: 271-296.

Brunborg, H. and Ø. Kravdal. (1986). "Barnetall blant norske kvinner. En paritetsanalyse basert på registerdata". Reports 86/27. Statistics Norway. OsloKongsvinger.

Brunborg, H. and S.E. Mamelund (1994). "Kohort- og periodefruktbarhet i Norge 18201993.” Reports 94/27. Statistics Norway. Oslo-Kongsvinger.

Crimmins E.M., R.A. Easterlin and Y. Sato. (1991). "Preference changes among American youth: family, work, and goods aspirations." Population and Development Review 17: 115-133.

Ermisch, J. (1989). "Purchased child care, optimal family size and mother's employment." Journal of Population Economics 2: 79-102.

Hoem, B. (1996). "The social meaning of education for third-birth fertility: a methodological note on the need to sometimes respecify an intermediate variable". Yearbook of Population Research in Finland 33: 333-339.

Hoem, B. and J. M. Hoem. (1989). "The impact of female employment on second and third births in modern Sweden." Population Studies 43: 47-67.

Hoem, J.M., A. Prskawetz and G. Neyer (2001). "Autonomy or conservative adjustment? The effects of public policies and educational attainment on third births in Austria, 1975-96". Population Studies 55: 249-261.

Huinink, J. (1989). "Das zweite Kind: Sind wir auf dem Weg zur Ein-Kind-Familie?" Zeitschrift fur Sociologie 18: 192-207.

Jejeebhoy, S. (1995). Women's education, autonomy and reproductive behaviour: Experience from developing countries. Oxford: Clarendon Press. 
Kravdal, Ø. (1992a). "The emergence of a positive relation between education and third birth rates in Norway with supportive evidence from the United States." Population Studies 46 (3) : 459-475.

Kravdal, Ø. (1992b). "Forgone labor participation and earning due to childbearing among Norwegian women." Demography 29: 545-563

Kravdal, Ø. (1992c). "The weak impact of female labour force participation on Norwegian third-birth rates." European Journal of Population 8: 247-263.

Kravdal, Ø. (1994). "The importance of economic activity, economic potential and economic resources for the timing of first birth in Norway." Population Studies 48: $249-267$

Kravdal, Ø. (1996). "How the local supply of day-care centers influences fertility in Norway: A parity-specific approach." Population Research and Policy Review .15: 201-218.

Kravdal, Ø. (2000). "The impact of individual and aggregate unemployment on fertility in Norway." Memorandum 2000/43. Department of Economics, University of Oslo.

Lillard, L, and C.W.A. Panis. (2000). aML Multilevel Multiprocess Statistical Software. Release 1.0. EconWare, Los Angeles, California

Martin, S.P. (2000). "Diverging fertility among U.S. women who delay childbearing past age 30." Demography 37: 523-533.

Ni Bhrolchain, M. (1993). "Period paramount? A critique of the cohort approach to fertility." Population and Development Review 18: 599-629.

Santow, G and M. Bracher. (2001). "Deferment of first birth and fluctuating fertility in Sweden." European Journal of Population 17: 343-363.

Statistics Norway. (1991). Familie- og yrkesunders $\phi k e l s e n$ 1988. NOS B 959. Oslo.

Wright, R.E., J.F. Ermisch, P.R.A. Hinde and H. Joshi. (1988). "The third birth in Great Britain.” Journal of Biosocial Science 20: 489-496.

Østby, L. (1989). "The diffusion of modern contraception in Norway and its consequences for the fertility pattern." European Journal of Population 5: 27-43. 
Demographic Research - Volume 5, Article 6 